\title{
VISCONDE DE VILA MOURA, LEITOR DE FIALHO DE ALMEIDA
}

\author{
VISCOUNT OF VILA MOURA, FIALHO DE ALMEIDA'S \\ READER
}

Duarte Braga*

Resumo: A recepção do escritor português Fialho de Almeida é bastante abundante entre o fim do século e o modernismo português, sobressaindo a obra Fialho de Almeida (1916) do Visconde de Vila Moura (1877-1935), título nobiliárquico de Bento de Carvalho Lobo. Genologicamente difícil de classificar, o livro de 1916 localiza-se entre a biografia e o ensaio, dotada de um pendor fortemente impressionista e digressivo. A obra é lida no contexto da obra do Visconde e comparada com outros momentos da recepção fialhiana.

Palavras-chave: Fialho de Almeida, Visconde de Vila Moura, Recepção

AвsтRACT: The reception of the Portuguese writer Fialho de Almeida is quite abundant between the end of the century and the Portuguese Modernism. In this period, stands out the work Fialho de Almeida (1916), authored by the Viscount of Vila Moura (18771935), title of Bento de Carvalho Lobo. Difficult to classify, the book of 1916 is located between biography and essay, with a strong impressionist and digressive nature. This essay aims to interpret this book in the context of Vila Moura's works, comparing it with other moments of Fialho's reception.

KeYwords: Fialho de Almeida, Visconde de Vila Moura, Reception

\footnotetext{
"Universidade de São Paulo/Fapesp. Pós-Doutor em Estudos Comparados de Literaturas de Língua Portuguesa (USP). Email: duartedbraga@gmail.com
} 
O In MeMoRIAM DE 1917 E A RECEPÇÃo DE FialHo de Almeida Após a sUa morTe

Os contemporâneos de Fialho de Almeida nele souberam reconhecer um dos autores cimeiros do fim-de-século português. O In Memoriam de $1917^{1}$ de António Barradas e de Alberto Saavedra ${ }^{2}$ é um poderoso indicador neste sentido e merecedor de texto analítico independente, sobretudo por se tratar do primeiro grande tentame crítico relativo ao autor de Vila de Frades. Embora fortemente memorialista, há contudo alguns textos de penetração hermenêutica, como o de António Sardinha, que importa ter em atenta consideração. Mas o mais digno de nota é que, mesmo no seio dessa dimensão essencialmente memorialística, nos deparamos com tópicos que se revelarão persistentes no campo da recepção crítica, denunciando preocupações comuns a muitos dos articulistas, bem como ao Visconde

\footnotetext{
${ }^{1}$ Principais colaboradores: Alberto Pimental, Albino Forjaz Sampaio, António Corrêa d'Oliveira, António Sardinha; Eugénio de Castro, Guerra Junqueiro, Lopes de Mendonça, Philéas Lebesgue e Ribera i Rovira, entre outros menos conhecidos. Refira-se também o ensaio, entre as páginas 71-98, do filólogo Cláudio Basto, "A linguagem de Fialho", ainda hoje insuperável como trabalho de recolha do léxico fialhesco. Sobre este assunto cf. também Franco 2002.

${ }^{2} \mathrm{O}$ site da Biblioteca Nacional (http://porbase.bnportugal. pt) atribui ao primeiro os anos de 1887-1945 como datas de nascimento e de morte. Tradutor e possivelmente médico, deixou (a ser o mesmo autor) obras sobre questões médicas no Ultramar. Já Alberto Saavedra (1895-1995) seria também médico e ao que parece docente universitário desta área no Porto. Será certamente o mesmo autor de A linguagem médica popular de Fialho editado em 1916a, no Porto, pela Tipografia da Renascença Portuguesa, mesma editora do In Memoriam. Brás Burity, homem de teatro que colaborou nesta obra, chama-lhes "dois rapazes inteligentes" com "vint’anos ingénuos" (BURITY, 1917, p. 56), o que confirmaria as datas veiculadas pela Biblioteca Nacional. Cf. textos dos organizadores inclusos no volume.
}

de Vila Moura, como já se verá. Atente-se, a este respeito, na seguinte passagem da apresentação do volume, da responsabilidade dos organizadores, onde se enumeram as principais dimensões da vida e da obra de Fialho nele contempladas: “(...) aspectos desconhecidos da sua vida, a sua nosografia, as principais qualidades da sua prosa, a sua linguagem, o seu estilo, alguns tipos da sua galeria, o seu exaltado sentimento da paisagem, a sua atitude poíitica, o problema da sua morte" (BARRADAS e SAAVEDRA, 1917, p. 6). Tratam-se de tópicos fortemente epocais, de natureza mais impressionista do que crítica, e que sintetizam o essencial das visões sobre este autor num período de poucos anos após a sua morte. Dentro destas, a questão do estilo assume particular importância pela insistência com que é abordada, manifestando-se no assombro dos colaboradores pela vitalidade estilística e imagética da escrita fialhesca, aspecto que adiante se tratará com pormenor. Devemos salientar, para já, que estes homens tinham - em momento (1917) de já seguro domínio dos Neo-Romantismos e de visibilidade da aç̧ão modernista - a percepção clara do papel de Fialho na renovação estilística da literatura portuguesa. Com efeito, o nosso autor em muito contribuiu, sobretudo em termos de prática literária, para o lento e incerto processo de derivação e superação do Naturalismo em multifacetada aproximação à constelação das estéticas pós-naturalistas³.

\footnotetext{
${ }^{3}$ Os livros de Fialho constituem verdadeiros marcos donde podemos avaliar a penetração das novas estéticas na literatura nacional, sobretudo no que tange à ficção. Como lembra Seabra Pereira: "Se 1893 é o ano em que, após Gouaches de João Barreira, a consagração dos no-
} 
O In Memoriam é assim um preito ao reconhecido criador de um estilo novo, moldável, vibrante e bem adaptado ao gesto sinestésico das novas escolas. No dizer do Visconde de Vila Moura, Fialho teria sido, com efeito, um revolucionário em Arte através precisamente do "segredo da sua forma, ainda tão exoticamente plástica” (VILA MOURA, 1916a, p. 118); mais do que isso, o criador de uma verdadeira "revolução estilistica" (VILA MOURA, $1916^{\mathrm{a}}$, p. 122) ${ }^{4}$.

Esta quase uníssona recepção da diferença estética de Fialho por parte dos seus coevos $^{5}$ é mais um dos sinais que aponta para a necessidade de, nos dias de hoje, aprofundarmos a redimensionação crítica do autor de Cidade do Vício na história da literatura portuguesa já proposta por autores como Pereira (2004), Mateus (2008) e Braga (2011). Esta reavaliação deve levar-nos a esquecer a ineficaz construção do epígono de Eça ou, quanto muito, do naturalista ambíguo que ainda surge, por exemplo, numa obra recente sobre o conto português: Van Achter (2010). Em seu lugar, devemos abraçar a noção de um Fialho cultor do novo, um verdadeiro pon-

vos estilos epocais se estende da poesia lírica para o conto e para os géneros híbridos em prosa (entre o modo lírico e o modo narrativo), em boa parte esse significado histórico fica a dever-se à edição de $O$ País das Uvas, de Fialho de Almeida" (PEREIRA, 2003, p. 158).

${ }^{4}$ Não chega, no entanto, a dizer em que consiste tal revolução, apontando apenas para o estilo proteico, bem como para o compromisso entre linguagem popular e erudita na página 130. Esta última nota não é, porém, mais do que um tópico da crítica desta época, como mais uma vez prova o In Memoriam, em variadíssimos momentos.

${ }^{5}$ Mesmo quando com contornos negativos: um dos tópicos da recepção fialhiana é a sua coprolalia ou linguagem escatológica. Sobre esta questão ver o capítulo introdutório de Mateus (2008). tífice das estéticas finisseculares, não só em termos estilísticos, mas também na partilha de vectores temáticos - Pereira (2004) - e até em dimensões genológicas, como defende Braga (2011), sendo no entanto de ressalvar que a herança naturalista se repercute nessa poliestesia-Braga (2011) - finissecular. Fialho assume outra grandeza quando élido à luz da grande vitalidade estética que este período manifestou em Portugal ${ }^{6}$ e no qual ele pontificou. O volume do Visconde de Vila Moura inteiramente dedicado ao nosso autor, sinaliza precisamente isso: a devoção estética ${ }^{7}$ por certas figuras que no seu tempo personificaram as contradições do fim de século, que é essencialmente o que ele - bem como o In Memoriam - valoriza em Fialho, tal como o que valorizará em António Nobre.

\section{FIALHO D'ALMEIDA DE VILA MOURA}

Para além de ficção, o Visconde de Vila Moura (1877-1935), título nobiliárquico de Bento de Carvalho Lobo, legou uma boa quantidade de obras genologicamente difíceis de classificar, entre a biografia e o ensaio com um pendor fortemente impressionista e digressivo, tais como a sua camiliana, ou os volumes António Nobre, de 1915 e Fialho d'Almeida de 1916, ambos editados pela Renascença Portuguesa. Segundo João Alves ${ }^{8}$, autor

\footnotetext{
${ }^{6}$ Cf. Pereira (2005, p. 45-58).

${ }^{7}$ Grafando sempre em maiúscula os termos Escriptor e Artista referindo-se a Fialho e avaliando-o sem restrições críticas como criador de "Arte pela Arte" (VILA MOURA, 1916a, p. 78).

${ }^{8}$ Este autor, que não conseguimos identificar com rigor, é alguém que também publicou na área do Direito. Claramente comprometido com a ideologia ruralista e reaccionária do regime que acabará em 1974, como fica
} 
do único ensaio de fôlego sobre o autor de Ancede, O génio de Vilamoura: Meditação sobre os problemas da literatura contemporânea (1937), estas duas obras integrar-se-iam numa suposta primeira fase, decadente, da obra do visconde, com o interesse de oferecerem "passagens (...) doutrinais" que informariam da "concepção do autor" (ALVES, 1937: 153). Fariam parte da dita fase: Nova Safo (1912), Doentes da Beleza (1913), Camilo Inédito (1913), Boémios (1914), António Nobre (1915) Grandes de Portugal, com António Carneiro (1916a), Fialho d'Almeida (1916a), As cinzas de Camilo (1917) e Fanny Owen e Camilo (1917), Os Últimos (1918) e Obstinados (1921). Quanto ao livro que aqui nos traz, nele de facto confluem o Decadentismo, patente no gosto pelo mórbido, extravagante e artificial, e uma herança naturalista em deriva decadentista. Já o quadro ideológico é vincado pelo aristocratismo social e estético - que também deve ser lido à luz da dita estética - do Artista (sempre grafado com maiúscula), que reside muito longe dos acenos da multidão e a verrina - de perfil monárquico e tradicionalista - contra o regime de 1910.

Há que valorizar o livro ora em apreço pelo que introduz, abrindo caminho ao In Memoriam, de tópicos que serão determinantes para a fortuna crítica de Fialho, havendo

claro a quem lê o livro, compreende mas desvaloriza o Decadentismo vilamourino. Por outro lado, afirma que a grande síntese decadentista em Portugal é feita por aquele autor, para depois ser superada pela ulterior aproximação ao ruralismo de herança neogarrettiana e convergência integralista-salazarista, se é que este não está já presente na fase decadentista. Obra curiosa e com uma certa riqueza, deixa várias pistas para a análise da obra do autor. Genologicamente, é uma mistura entre uma entrevista (que acompanha o autor até à sua morte) seguida dum ensaio crítico. no entanto que assinalar o seu pendor mais indicativo do que hermenêutico, plasmado numa sintaxe retorcida e obscura. A obra insere-se claramente na linha finissecular, atrás referida, de valorização do Artista do estilo em detrimento do panfletário. Com efeito, presta pouca atenção a este último, desvalorizando-o segundo um tópico ubíquo: a sua violência e suposta incoerência, registo que vamos também encontrar no In Memoriam. Mas há que ter em conta que a oposição entre dois Fialhos é uma construção - cuja origem possivelmente data desta fase da recepção ou anterior - que deve ser desconstruída. Ficamos perante um homem bifronte, em parte demónio-crítico e em parte anjo-artista cinzelador da palavra. Já no curioso Grandes de Portugal, do mesmo ano $(1916 a)^{9}$, feito em pareceria com António Carneiro, Fialho aparece como "Obra de Deus e de Satan em carrara e barro" (VILA MOURA, 1916b, p. 76), que um parágrafo de Guerra Junqueiro parece glosar ${ }^{10}$ no In Memoriam. Por sua vez, a ideia ecoa, já sem a imagem da escultura dúplice, nas Memórias de Raul Brandão ${ }^{11}$. Diz o autor de Os Simples:

\footnotetext{
${ }^{9}$ Grandes de Portugal é um conjunto de breves sentenças entre o mordaz e o devoto, sobre escritores contemporâneos portugueses, cada uma delas acompanhada de uma gravura de António Carneiro. Parte do texto havia já sido publicado com o título "Veneras" no ${ }^{\circ} 3$, de 6 de Janeiro de 1915 da revista Galera, dirigida por Afonso Duarte, na página 2. Esta obra, curiosa e original, pode funcionar como uma espécie de chave ou de arquétipo para ler os livros críticos do visconde. Lembra Pascoaes pela transfiguração alegorizante dos personagens e pela oposição dinâmica de imagens simbolicamente contrárias, como Deus ao Diabo.

${ }^{10}$ Será este um fragmento de um texto maior de Guerra Junqueiro aproveitado pelos organizadores do In Memoriam ou uma contribuição original para o volume?

${ }^{11}$ "Deu-lhe Deus o mais rico quinhão que imaginar se
} 
Em Fialho de Almeida há um poeta genial e um noticiarista sacrílego. Sacrílego, porque gastou uma parte do seu génio, isto é, da sua imortalidade, a contar coisas fúteis e ruins, que viveram instantes ou que nasceram mortas. De metade dum bloco de mármore fez Beleza. A outra metade estilhaçou-a e converteu-a em pó (JUNQUEIRO, 1917, p. 34).

A crítica ao Fialho polemista, em clave fortemente biografista, é algo que acabou por envenenar, como se vê, a recepção do autor: olhar para ele à luz do mais agressivo que houve no "noticiarista", como o fizeram, entre vários exemplos possíveis, Régio (s/d) ou Ferreira (1979), mesmo quando se reconheceu o valor estético da sua crítica, como em ambos os casos. Trata-se - seguindo aqui Isabel Mateus (2008) - de uma visão ético-moral que esconde um repúdio à radicalidade da crítica fialhiana à sociedade burguesa. Esta visão, diríamos nós, é que opera a construção de uma duplicidade imaginária entre o crítico e o ficcionista que não é mais do que uma forma de não reconhecer a coerência interna de toda uma obra, sendo um dos óbvios aspectos dessa coerência as próprias virtualidades estéticas do texto crítico, em sintonia com uma obra ficcional cuja vitalidade imagética os seus coevos no entanto entreviram. A respeito de tudo isto cite-se Isabel Mateus, concludentemente:

pode, a língua incomparável para exprimir a quimera e a dor, e esse macaco sem fé esbanjou-a com o mais absoluto impudor: serviu-lhe para a chacota. Transtornou tudo, engrandeceu tudo, riu-se de tudo (...)" (BRANDÃO, 1998, p. 67).
Desde sempre se tem insistido (...) em apontar uma incoerência ou 'bipolaridade fundamental' entre o homem e o escritor, entre a vida e a obra, relegando para segundo plano a coerência e o significado ideológico e literário desta última (MATEUS, 2008, p. 18-19).

No caso de Vila Moura, a razão principal que lhe fará desagradar os excessos do polemista é que estes acabaram por ser uma boa ajuda para aumentar o caos na Res Publica, ainda que pareça suspeitar do investimento estético por detrás da actividade crítica do autor de Os Gatos: "Consciente ou inconscientemente foi, como todos os panfletários, um Orpheu da Rua, pelo menos ate se sentir sacudido por ela" (VILA MOURA, 1916a, p. 64). É precisamente como um esteta visionário, de amplos recursos, que Fialho interessa ao autor nortenho, em valorização presciente da sua modernidade através do índice da fragmentariedade que acha na obra: "toda a beleza maravilhosa e não raro inconsequente da sua obra de apontamentos" (VILA MOURA, 1916a, p. 12).

É assim que Vila Moura se diferencia de uma certa linha dentro da recepção, perplexa perante o grande número de recursos estético-estilísticos por ele empregues. Estes devem na verdade ser entendidos sobretudo como marca da dimensão adaptativa da obra fialhesca em relação a diversas escolas e tradições literárias finisseculares, em processo de releitura da tradição naturalista ${ }^{12}$. Aquela linha crítica, formada ao longo do século XX, dedicou-se muitas vezes a emitir juízos entre

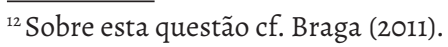


si abertamente contraditórios, o que não se explica apenas pelo ecletismo da obra, mas pelo facto de bastas vezes visarem uma leitura da sua totalidade de acordo com uma só escola literária, ou pela modalização de determinada escola, o que é apenas possível preterindo certos aspectos da literatura de Fialho em relação a outros ${ }^{13}$. Já os autores seus coevos parecem ter tido menos dificuldade em encarar este lado errante e aparentemente incoerente de Fialho, como Vila Moura e o In Memoriam parecem mostrar. Uma excepção, contudo, é António Sardinha, que classifica Fialho como: "Talento feito de arrancos e de inquietações arrojadas". À sua obra faltaria "uma ideia orgânica que lhe imprima unidade e consistência dorsal" (SARDINHA, 1917,

\footnotetext{
${ }^{13}$ É fácil constatar a profusão de etiquetas estético-periodológicas nos estudos fialhescos. Uns poucos exemplos serão suficientes para mostrar, sem exaustividade, a confusão reinante no que toca à catalogação do autor. Temos de facto assistido às escolhas por parte da crítica entre as três grandes etiquetas de romântico, naturalista e decadentista, com algumas modulações ou combinações conciliatórias por vezes inesperadas: "romântico materialista-sensorial"; "exemplo típico de realismo integrado, refractado num temperamento romântico" (COELHO, 1977, p. 151); "Parnassien par l'ideal esthétique, naturaliste par filiation” (MARTINS, 1954, p. 6). Já um estudioso como Gaspar Simões opta pelo esteticismo finissecular, ainda que nele reconheça um fenómeno de fusão com o realismo (SIMÕES, 1987, p. 572) Procurando compreendê-lo pelo seu carácter futurante - inserindo-o em correntes de que seria em Portugal o precursor - temos depois o pré ou o para-Expressionismo com Lopes (1987) e Lourenço (2004) e o pré-Surrealismo com Lopes (1987), entendidos enquanto desenvoluções ou transmutações imprecisas do Naturalismo. Já Mateus (2008) defende o Expressionismo de Fialho enquanto estética da expressão versus a estética da representação realista e naturalista, que refuta convincentemente como "erro global" (MATEUS, 2008, p. 40) da crítica. Em síntese, a catalogação de Fialho tornou-se uma questão altamente complexa, como admite a mesma autora: "Embora 'rotulada' e arquivada na prateleira do Naturalismo, a obra de Fialho continua a surpreender os leitores e a desafiar qualquer rígida vinculação periodológica, ideológica ou estética" (MATEUS, 2008, p. 42).
}

p. 42). Ao contrário do autor integralista, Vila Moura, salientando a individualidade literária de Fialho, insiste no carácter "tumultuário" e incorente da sua arte, que valoriza, pressentindo-o como um signo da Modernidade, embora acabando por lê-lo como sintoma de uma fundamental incoerência psíquica e biográfica ${ }^{14}$. Teremos que esperar, contudo, por Mateus (2008), para ver este fenómeno analisado de forma consistente, aí se identificando as dificuldades de catalogação da obra fialhiana com o facto de nela se cruzarem várias estéticas pós-naturalistas, ainda que acabe por identificá-la com uma pulsão fundamentalmente próxima do Expressionismo. Outra produção ensaística - como Lopes (1987), Bernardes (2001) e Braga (2011) - tentará explicar o mesmo facto sobretudo por uma atitude experimental. De qualquer maneira, é seguro afirmar que é como Isabel Mateus cabalmente demonstrou (2008) - pela capacidade transfiguradora do real, suportada por um uso muito particular da linguagem e pelo desenvolvido arcaboiço estilístico-metafórico, que Fialho se afasta, ao longo do seu percurso, do Naturalismo de escola e do inverificado epigonismo em relação a Eça $a^{15}$.

Com efeito, o afastamento em relação ao Naturalismo é sentido por vários dos seus

\footnotetext{
${ }^{14}$ Por exemplo, nesta passagem: "Para mim esse tipo de histérico e fragmentado, contraditório e presciente que figurou no Manuel é fundamentalmente ele próprio, desdobrando-se por escrever a sua mesma «duplicidade cerebral» e gritar contra a desgraça do outro, «o que morrera» e agora eu sabia ali, sem que ao menos pudesse precisar onde" (VILA MOURA, 1916a, p. 29-20).

${ }^{15}$ Segundo Vila Moura, Fialho foi um revolucionário do estilo, junto com outros autores da sua geração. Assim, aparece ombreando com Junqueiro, Eça e até Bordalo.
} 
contemporâneos, o visconde incluído, ao nível da intensidade emotiva e violência quase expressionista - segundo Lourenço (2004) e Mateus (2008), mas já sugerido por Sardinha (1917) - da escrita fialhiana. A insistência dos colaboradores do In Memoriam na questão da emotividade é uma forma pré-crítica, chamemos-lhe assim, ou acrítica de o apontar ${ }^{16}$. Já em trecho dedicado a Fialho na segunda obra do autor de Ancede, A vida mental portuguesa. Psychologia e arte (1908), ele é evocado de forma distanciada do panorama da estética naturalista em Portugal:

Temos para nós, como já dissemos, que a Arte é em grande parte rebelde. E em Portugal, hoje, ninguém como Fialho encarna esta rebeldia dando, na mesma publicação, como nos Gatos, prosa e ideia que bem pode instruir uma nova escola satânica e paginas como aquelas da monografia - Manuel - que são a verdadeira elegia do génio da desgraça. Digam o que disserem, não o tomamos como observador indiferente. Pelo contrário, a sua obra é toda imprevista. Sente-a e muito intensamente. É apaixonado ao demolir e ainda quando adere (VILA MOURA, 1908, p. 20).

De base naturalista, em forte convergência com o Decadentismo, é também a própria leitura que para Vila Moura haveria de forjar para explicar para a diferença de Fialho. Antes de mais, os dilemas internos ou "neurilidade" (VILA MOURA, 1916a, p. 35) do seu psiquismo explicar-se-iam pelo

\footnotetext{
16 "Depois de Camilo, não houve ainda, na literatura portuguesa, um mais emotivo espírito e uma mais comovida e abrasada sensibilidade. (CASTRO, 1917, p. 54). Cf. também, por exemplo Pimentel (1917, p. 16).
}

cruzamento de duas raças no seu sangue, a alentejana e a beirã, o que lhe surge como revelação numa visita a Vila de Frades, onde se depara com o irmão de Fialho:

Deparou-me o acaso com um novo documento a instruir a história do génio do Artista na pessoa do irmão (...) em que, não sei porque, pressenti a elegia viva da arte mais esquisita e mórbida de Fialho, qualquer coisa da neurilidade extravagante dos seus doridos, aquela que animou os seus personagens tão suavemente fatais e andróginos (VILA MOURA, 1916a, p. 12).

Esta descoberta das origens de Fialho leva Vila Moura a sublinhar a radicação a sul da sua literatura como pretexto para lhe atribuir uma fantasiosa radicação árabe que explicaria todo o "sonho luxurioso" da sua obra (VILA MOURA, 1916a, p. 38), curiosa explicação de índole decadentista, com contornos irracionalistas e orientalistas, que ultrapassa o inicial enquadramento naturalista:

De facto, entre os grande plásticos da Península, quem mais que o grande Artista conseguiu ainda praticar um semelhante ou equivalente embrenhado de esmaltes e de linhas, o segredo da luz e da cor, idêntica riqueza no processo de exprimir Arte, toda aquela ânsia de vida luxuriosa que ergue o mais da obra árabe e em que domina sempre, ao lado do culto do individuo, considerado na sua religiosidade como no seu luxo, a preocupação álacre do supremo culto da natureza" (VILA MOURA, 1916a, p. 42) 
Como fica claro pela citação, as implicações sinestésicas desta figuração servem para valorizar o picturalismo paisagístico, associando-o à intensidade emotiva do gesto da escrita, isto é, às próprias virtualidades de superação do Naturalismo. Trata-se de um verdadeiro tópico desta época, o paisagista, com vitalidade garantida até um Bernardo Soares, e que não deixa de ecoar no In Memoriam ${ }^{17}$. A crítica desta época foi de facto muito sensível ao colorista de paisagens, no que ele se torna, para o visconde, um veículo da grande Arte:

Assim, também, talvez nenhum dos escritores do seu tempo conseguisse surpreender a Arte dos eterizados e estranhos cumes donde ele se deu a vertiginá-la. É ver as paisagens, quasi irreais do seu lápis de crayonista; as suas figurinhas histéricas de branda genealogia bíblica; os seus aleijados; as suas porcelanas, como todo o mundo fantástico da sua inigualável Arte! (VILA MOURA, 1916a, p. 125).

Na sua actividade estética, o escritor é descrito por Vila Moura sempre como um pintor. Por exemplo, na novela A Ruiva, ele é um Zurbarán (VILA MOURA, 1916a, p. 86) dedicando-se a figuras sombrias e lívidas. Aquele texto é assim menos uma novela do que "a primeira galeria de figuras da sua maneira estranha de pintar" (VILA MOURA, 1916a, p. 86). Assim, se por um lado, o nome do autor se ligou às artes plásticas por ter sido um crítico muito receptivo às estéticas que transcenderam o Naturalismo de escola;

\footnotetext{
${ }^{17}$ Também se encontra no referido texto de Sardinha, e em outros do mesmo volume, como em Santa Rita (1917, p. 39-41).
}

por outro, e como já sugerimos, é este um topos que faz apelo sobretudo à dimensão fortemente inovadora do seu descritivismo e do que desse poder picturalista pesou sobre a recepção em Portugal das estéticas finisseculares, de facto fazendo com que o nome de Fialho de Almeida fosse reconhecido no meio literário português do seu tempo como o escritor artiste por excelência.

\section{REFERÊNCIAS}

ALVES, João. O génio de Vilamoura: meditação sobre os problemas da literatura contemporânea. Porto: Livraria Tavares Martins, 1937.

BARRADAS, António; SAAVEDRA, Alberto, eds. Fialho de Almeida: In Memoriam. Porto: Tipografia da «Renascença Portuguesa», 1917. BERNARDES, José Augusto Cardoso. Fialho de Almeida: Uma estética de tensões. In: História da Literatura Portuguesa, volume V. Lisboa: Alfa, p. 293-308.

BRAGA, Duarte Drumond. A questão estéticogenológica em Fialho de Almeida: propostas de investigação em torno da contística e da forma breve. In: FRANCO, António Cândido (org.). Fialho de Almeida. Cem anos depois. Évora: Licorne, 2011, p. 57-68.

BRANDÃO, Raul. Março-1903. In: Memórias, tomo 1, ed. José Carlos Seabra Pereira. Lisboa: Relógio d'Água, 1998, p. 66-78.

BURITY, Brás. O culto de Fialho. In: BARRADAS, António; SAAVEDRA, Alberto, eds. Fialho de Almeida: In Memoriam. Porto: Tipografia da «Renascença Portuguesa», 1917, p. 56-62.

CASTRO, Augusto de. Fialho de Almeida. In: BARRADAS, António; SAAVEDRA, Alberto, eds. Fialho de Almeida: In Memoriam. Porto: 
Tipografia da «Renascença Portuguesa», 1917, p. 54.

COELHO, Jacinto do Prado. Fialho e as correntes do seu tempo. In A Letra e o Leitor. Lisboa: Moraes, 1977, p. 149-161.

FERREIRA, Vergílio. Do mundo original. Lisboa: Bertrand, 1919, p. 197-198.

FRANCO, António Cândido. 0 essencial sobre Fialho de Almeida. Lisboa: Imprensa NacionalCasa da Moeda, 2002.

JUNQUEIRO, Guerra. Fialho. In: BARRADAS, António; SAAVEDRA, Alberto, eds. Fialho de Almeida: In Memoriam. Porto: Tipografia da «Renascença Portuguesa», 1917, p. 134.

LOPES, Óscar. Fialho. In: Entre Fialho e Nemésio, volume 1. Lisboa: Imprensa NacionalCasa da Moeda, 1987, p. 173-196.

LOURENÇO, Eduardo. Cultura Portuguesa e Expressionismo. In: A Nau de Ícaro seguido de Imagem e Miragem da Lusofonia. Lisboa: Gradiva, 2004, p. 23-35.

MARTINS, António Coimbra. Portrait de Fialho [Sep. Bol. des Études Portugaises]. Coimbra: Coimbra Editora, 1954.

MATEUS, Isabel Cristina de Brito Pinto. 'Kodakização' e Despolarização do Real: para uma poética do grotesco na obra de Fialho de Almeida. Lisboa: Caminho, 2008.

PEREIRA, José Carlos Seabra. Fialho de Almeida. In: História da Literatura Portuguesa, volume VI: Do Simbolismo ao Modernismo. Lisboa: Publicações Alfa, 2003, p. 156-158.

- Rumos de narrativa breve prémodernista. Forma Breve, $\mathrm{n}^{0} 2-\mathrm{O}$ poema em prosa. Aveiro: Universidade de Aveiro, p. 45-58. PIMENTEL, Alberto. Palavras Sinceras. In: BARRADAS, António; SAAVEDRA, Alberto, eds. Fialho de Almeida: In Memoriam. Porto:
Tipografia da «Renascença Portuguesa», 1917, p. 16-17.

RÉGIO, José. Fialho crítico de teatro. In: Estrada Larga, vol. 3. Porto: Porto editora, s/d., 168-172.

MARTINS, A. M. Rita. A morte do solitário de Vila de Frades. BARRADAS, António; SAAVEDRA, Alberto, eds. Fialho de Almeida: In Memoriam. Porto: Tipografia da «Renascença Portuguesa», 1917, p. 39-41.

SARDINHA, António. Fialho de Almeida. In: BARRADAS, António; SAAVEDRA, Alberto, eds. Fialho de Almeida: In Memoriam. Porto: Tipografia da «Renascença Portuguesa», 1917, p. 42-53.

SIMÕES, João Gaspar. Genealogia do conto moderno (1861-1915). In Perspectiva Histórica da Ficção Portuguesa (das origens ao Século XX). Lisboa: D. Quixote, 1987, p. 539-626.

VILA MOURA, Visconde de. Fialho d'Almeida. Porto: Edição da Renascença Portuguesa, 1916a. ;António Carneiro. Grandes de Portugal. Porto: Renascença Portuguesa, 1916b.

A vida mental portuguesa. Psychologia e arte. Coimbra: Imprensa da Universidade, 1908.

VAN ACHTER. On the Nature of the [Portuguese] Short Story: A Poetics of Intimacy. http://igitur-archive.library.uu.nl/ dissertations/2010-0114-200216/van-achter. pdf (consultado 20 Março, 2012).

Recebido para publicação em 14 nov. 2016. Aceito para publicação em 30 dez. 2016. 